\title{
Implementasi Model Timmons dalam pembinaan startup berbasis teknologi pada inkubator bisnis
}

\author{
Cut Irna Setiawati* \\ Administrasi Bisnis, Universitas Telkom \\ J1. Telekomunikasi 1. Bandung. 40257. Indonesia \\ irnacut@telkomuniversity.ac.id \\ Putri Meuthia Pratiwi \\ Administrasi Bisnis, Universitas Telkom \\ Jl. Telekomunikasi 1. Bandung. 40257. Indonesia \\ putrimeuthiapratiwims@gmail.com \\ *Penulis Korespondensi
}

Submitted: May 15, 2019; Reviewed: May 28, 2019; Accepted: Nov 5, 2019

\begin{abstract}
In 2013 Indonesia has developed Bandung Techno Park (BTP) as the business incubator and develop Startup Corner (SC) program. SC has four main phrases, such as Registration, Selection through Presentation, Pre Incubation, and Implementing Incubation Process. However, SC has not been maximized in identifying aspects of opportunities, teams and resources. The purpose of this research is to know the role of $S C$ in developing in relation with opportunity, team, and resources aspects. This research used descriptive qualitative method, with Timmons Model approach. The sample of this research is SC members and BTP supervisor by using structural interview with informans. As the results, the role of SC on the dimension of idea has played for product development, business model, and selling price. Market demand dimension is directing customer translation so that can assist in reaching customer opportunity and expanding market reach. Furthermore the role of SC in developing startup of team aspect based on leader dimension and team quality. The SC through training program has purposed to shape the entrepreneurial character during Pre Incubation activities. In creating the quality of the team submitted by setting an advisable work discipline in accordance with the BTP working hours other than that Startup Corner helps in disseminating recruitment information for startup requiring members. The role of SC in developing startup from the aspect of resources has provided physical facilities, then assistance to make the legality of a business entity, patent but there is no funding for the sustainability of a startup, then diverted in incubation or other programs. SC arranges all the sections for startup participants and has a good results but the final maitenance would take effort from the startups itself, because BTP only supports them and building the business model in techonology in short time.
\end{abstract}

Keywords: opportunity; resource; startup corner; team

Abstrak: Pada 2013 Indonesia telah mengembangkan Bandung Techno Park (BTP) sebagai inkubator bisnis dan mengembangkan program StartupCorner (SC). SC memiliki empat frase utama, seperti Pendaftaran, Seleksi melalui Presentasi, Pra Inkubasi, dan proses Inkubasi. Namun, SC belum pernah dianalisis dari aspek peluang, tim, dan sumber daya secara startup yang dihasilkan kurang maksimal. Tujuan dari penelitian ini adalah untuk mengetahui peran SC dalam mengembangkan peluang, tim, dan aspek sumber daya. Penelitian ini menggunakan metode deskriptif kualitatif, dengan pendekatan 
teori Model Timmons. Sampel dalam penelitian ini adalah 5 peserta SC dan supervisor BTP. Sebagai hasilnya, peran dimensi telah bertujuan untuk pengembangan produk, model bisnis, dan harga jual. Dimensi pasar permintaan adalah mengarahkan menerjemahkan apa yang diinginkan pelanggan sehingga dapat membantu dalam mencapai peluang pelanggan dan memperluas jangkauan pasar. Selanjutnya, peran SC dalam mengembangkan tim startup didasarkan pada dimensi pemimpin dan kualitas tim. SC melalui program pelatihan bertujuan untuk membentuk karakter kewirausahaan selama kegiatan Pra Inkubasi. BTP merekomendasikan jam kerja kepada semua anggota SC agar dapat membantu dalam menyebarkan informasi rekrutasi yang bermanfaat bagi startup. Peran berdasarkan pengembangan sumber daya terlihat pada tersedianya fasilitas fisik, kemudian bantuan untuk membuat legalitas entitas bisnis, paten tetapi tidak ada dana untuk keberlanjutan startup, kemudian dikonversi menjadi inkubasi atau program lain. SC mengatur semua bagian untuk startup dan memiliki hasil yang baik namun untuk menjadi keberlangsungan hidup startup diserakan kepada mereka masing-masing, karena BTP hanya mendukung dan membantu membangun model bisnis dalam teknologi bagi dalam waktu singkat.

Kata kunci: peluang; startup corner; sumber daya; tim

\section{PENDAHULUAN}

Teknologi memiliki kapasitas untuk menjaga agar biaya operasional rendah dan sebagai inovasi dalam memperbaharui teknologi yang dibutuhkan (Wei, Zhu, Deng, \& Yu, 2014:35).Inovasi tidak selalu identik mengenai Research and Development (R\&D) tetapi pengetahuan, kebutuhan, dan keinginan pasar (Bessant \& Tidd, 2007:90). Keberlangsungan kewirausahaan didukung dengan perkembangan teknologi (Brem \& Borchardt, 2014:17).

Menurut Shane \& Venkataraman (2003); dalam Siyanbola (2011:62), ikatan antara kewirausahaan dan teknologi yang memahami suatu proses bisnis dan mengenal peluang dan inovasi teknologi disebut Technology Entrepreneurship atau Technopreneurship yang bertujuan untuk menciptakan sebuah nilai ketidakpastian dan risiko yang akan timbul pada teknologi (Brem, 2008; dalam Brem \& Borchardt, 2014:19).

Pada era 2000 Technopreneurship mulai tumbuh kembali, hal ini didorong dari kawasan ekosistem inovasi dan infrastruktur teknologi yang semakin maju terbukti dengan pengguna internet di Indonesia (Arjanti \& Mosal, 2012:61). Pengguna internet di Indonesia berada pada peringkat ketiga dengan jumlah 133.700 .000 dan penetrasi hingga mencapai 51,4\%.

Di Amerika salah satu motivasi mendirikan bisnis yakni hadirnya kawasan Silicon Valley. Silicon Valley adalah nama untuk sebuah daerah yang berada di Selatan San Fransisco, California Utara (Hasbullah, 2015:12). Silicon Valley terbentuk pada tahun 1950. Di kawasan tersebut ratusan perusahaan bergerak di bidang teknologi dengan terobosan terbaru sehingga menjadi rumah perusahaan teknologi informasi raksasa dunia dengan budaya kerja yang desentralisasi.

Menurut Ries (2011:33) "A startup is a human institution designed to create a new product or service under conditions of extreme uncertainty". Menurut Milstein (2014); dalam Saputra (2015:4) risiko yang dihadapi bagi startup yakni risiko teknikal, risiko customer, dan risiko model bisnis. Oleh sebab itu, banyak perusahaan teknologi informasi dan startup bergabung di Silicon Valley untuk mengurangi risiko, membantu dalam mengarahkan bisnis yang sedang dijalankan, kesempatan kerjasama terbuka, serta mendapatkan informasi teknologi dan tren terbaru. Oleh karena itu, di dalam kawasan Science and Technology Park terdapat pusat inovasi yaitu inkubator (Philllimore \& Joseph, 2003 dalam Isabelle, 2014:69).

Inkubator merupakan program durasi tertentu untuk membantu mengidentifikasi lebih lanjut ide startup, memberikan dukungan mentor, dan penyediaan fasilitas (Phillimore, 2013:227). Program inkubator sangat cocok untuk membangun peluang agar dapat mempertajam ide dan model bisnis sebelum dipresentasikan depan investor. Seperti, inkubator yang unggul adalah Y Combinator, program yang didirikan pada tahun 2005 dan telah berhasil mendanai 500 perusahaan termasuk Dropbox, Airbnb, dan Stripe. Program ini dilaksanakan selama 3 bulan dan umpan balik dari startup 
yang bergabung di Y Combinator yaitu mengambil 6\% dari ekuitas perusahaan (Berkowski, 2016: 203).

Pada tahun 2013 Indonesia telah mengembangkan Science Techno Park di antaranya Batam Techno Park dan Palembang Techno Park (sedang dalam tahap pengembangan). Perbedaan yang diinisiasi terbentuknya Science Techno Park di Indonesia di antaranya Batam Techno Park dan Solo Techno Park diinisiasi oleh pemerintah daerah, sedangkan Cikarang Techno Park oleh pelaku bisnis (Aditya, 2016:19). Pada tanggal 19 Januari 2010 Bandung Techno Park diresmikan oleh Menteri Perindustrian. Bandung Techno Park diinisiasi oleh universitas dan pemerintah yang bergerak di bidang teknologi informasi dan komunikasi (Soenarso, Nugraha, \& Listyaningrum, 2013:39) untuk menciptakan sinergitas antara universitas, pemerintah, dan industri.

Selain itu, Bandung Techno Park (BTP) hadir untuk mendukung program pemerintah yaitu Pembangunan 100 Science Technlogy Park (STP) di Indonesia yang tertuang dalam Nawa Cita Presiden Jokowi dan di dalam RPJMN 2014-2019 (Adhitama, 2015:26). Saat ini, BTP dijadikan role model STP di Indonesia oleh Menristekdikti pada tanggal 23 Januari 2015. Dalam bagian BTP terdapat inkubator bisnis yaitu StartupCorner (www.bandungtechnopark.com, 2016).

StartupCorneryang dibawahi oleh Technology Business Inkubation diharapkan mampu mewujudkan visi dan misi dari BTP. Fasilitas yang disediakan oleh StartupCorner untuk menunjang kinerja startup yaitu ruang kerja, kantin yang sehat, bersih dan halal, 3D printing sebagai pendukung pembuatan prototyping, fasilitas olahraga, serta peluang untuk pendanaan dari berbagai sumber salah satu dari Indigo.

Program StartupCorner harus memiliki tahapan untuk bergabung dimulai dari registrasi, seleksi melalui presentasi produk, dan tim. Kemudian pra inkubasi, tujuan diadakan pra inkubasi untuk mengenal lingkungan kawasan BTP. Selanjutnya melaksanakan inkubasi yang nanti akan dilakukan soft launching artinya produk atau startup telah siap untuk dipasarkan dan nantinya pihak pengelola akan membantu untuk menghubungkan dengan relasi sesuai produk atau bisnis yang ditawarkan. Berdasarkan hasil wawancara dengan Ibu Lilies, Manajer Sumber Daya Manusia BTP bahwa saat ini per November 2016 tercatat 14 Startup yang bergabung yaitu Idsys, Narutindo, Sociocaster, Smash, Kemas Aja, Ikatali, Pasar Laut.com, Modegi, Bdg Techno Energi, Bdg Techno Industri, Bumbo, Sebuku, Orent, RadoCare, dan Semogaberkah. Fokus dari StartupCorner memberikan edukasi bagi pemula mengembangkan startup berbasis teknologi.

Menurut Eko Rahayu sebagai informan peneliti (2016) pada tahap pembekalan yang dilakukan oleh StartupCorner terhadap pengembangan tim diimplementasikan dengan mengadakan mentoring. StartupCorner telah mengadakan pelatihan pembentukan karakter kewirausahaan tetapi diadakan pada saat pra inkubasi. Pelatihan pembentukan karakter kewirusahaan diharapkan berkelanjutan tidak hanya diadakan saat Pra Inkubasi. Fasilitas yang diberikan sesuai pendanaan StartupCorner berdasarkan alokasi dana BTP untuk inkubator tersebut. Sehingga keberlangsungan StartupCorner dalam jangka pendek tidak dapat memperkuat startup secara teknis. Sehingga, tidak terdapat pendanaan untuk setiap startup yang telah lolos seleksi. Dana yang diberikan berupa penunjang mengikuti kegiatan di luar dari StartupCorner misal kompetisi atau kegiatan akselerator, dana tersebut diberikan untuk biaya skala kecil misal biaya server dan domain.

Dari segi legalitas StartupCorner tidak tersedia sehingga startup yang bergabung membentuk legalitas pihak Startup Corner berusaha membantu pencarian notaris. Oleh karena itu, StartupCorner belum mampu mengikuti kesuksesan Y Combinator. Sebab, sampai saat ini hanya 14 startup yang bergabung. Lima di antaranya telah mendapatkan pendanaan lebih dari Indigo atau lembaga lainnya. StartupCorner belum maksimal dalam mengidentifikasi aspek peluang, tim, dan sumber daya. Sejatinya, inkubator menyediakan coworking space, pelayanan konsultasi, akses internet, fasilitas data centre, pendanaan, dan kesempatan membangun jaringan dengan inkubator atau lembaga lain (Wei, Zhu, Deng, \& Yu, 2014: 40). Padahal menurut Model Timmons dalam sebuah usaha atau bisnis harus mampu menyeimbangkan aspek peluang, tim, dan sumber daya.

Namun, belum ada analisis terhadap StartupCorner dengan pendekatan Model Timmons. Hal tersebut seharusnya dapat dilakukan oleh pihak StartupCorner untuk membantu startup dalam menyeimbangan aspek peluang, tim, dan sumber daya. Apalagi proses kewirausahaan memiliki sifat yang dinamis.

Penelitian ini memiliki rumusan masalah terkait bagaimanakah peran Startup Corner dalam mengembangkan startup dari aspek peluang, tim, dan sumber daya. Dengan tujuan penelitiannya 
adalah mengidentifikasi aspek peluang, tim, dan sumber daya StartupCorner dengan pendekatan Model Timmons.

Technology Entrepreneurship atau Technopreneurship mempertimbangkan ikatan antara kewirausahaan dan teknologi (Shane \& Venkataraman, 2003; dalam Zupic, 2014:1) Technopreneurship merupakan kewirusahaan berbasis teknologi yang tidak lepas dari komersialisasi dan inovasi teknologi. Pendekatan Technopreneurship dalam manajemen dapat meningkatkan peluang, komersialisasi, mengelola percepatan pertumbuhan perusahaan, mengelola risiko yang terjadi, kemampuan pengambilan keputusan, dan mengumpulkan sumber daya baik(Brem \& Borchardt, 2014:19).

Teori yang dipaparkan Ries (2011:33) "A startup is a human institution designed to create a new product or service under conditions of extreme uncertainty" Didefinisikan bahwa startup ialah individu, perorangan, atau perusahaan. Untuk menciptakan produk atau jasa yang baru dalam menghadapi ketidakpastian yang tinggi sangat dibutuhkan manajemen yang terbarukan. Startup pada hakikatnya dinamis dan inovatif. Menurut Rhonda (2012:3); dalam Sitepu (2016:92) startup bisnis merupakan istilah dari bisnis yang baru yang memiliki peluang untuk tumbuh dan berkembang.

Inkubator memahami dinamika bisnis dan kebutuhan yang dihadapi perusahaan teknologi. Inkubator menyediakan ruang kantor gratis, pelayanan konsultasi, akses internet, fasilitas data centre, pendanaan, dan kesempatan membangun jaringan dengan inkubator atau lembaga lain (Thérin, 2014:28). Inkubator sebagai program pelatihan dan pembinaan kewirusahaan dengan periode tertentu bertujuan untuk membantu mengidentifikasi lebih lanjut ide startup, memberikan dukungan mentor, dan penyediaan fasilitas (Hisrich, 2008:24). Program inkubator sangat cocok untuk membangun peluang agar dapat mempertajam ide dan model bisnis sebelum dipresentasikan di depan investor (Mason \& Strak, 2004:230). Inkubator berfokus pada pengembangan usaha baru, sementara Science and Technology Park bertujuan dalam konsentrasi membangun bisnis atau industri di suatu kawasan (Isabelle, 2014:71) Secara umum peran inkubator mendukung perusahaan baru yang berbasis teknologi (Pauwels \& Charlotte, 2016:44)

Secara terminologi, pusat inovasi ialah inkubator yang dekat dengan universitas, kemungkinan berlokasi di dalam Science and Technology Park (Philllimore \& Joseph, 2003; dalam Isabelle, 2014:69). Sebagai contoh, inkubator yang unggul adalah Y Combinator program didirikan pada tahun 2005 yang merupakan bagian dari Science and Technology Park yaitu Silicon Valley (Rahman, 2012:7). Menurut Bergek \& Norrman (2008); dalam Saputra (2015:7-8) ada tiga fase inkubator yaitu fase pertama Rintisan, sebuah inkubator memiliki persyaratan yang tidak ketat, inkubator ini masih baru. Fase Kedua Pengembangan Bisnis, fokus utama pengembangan kewirausahaan oleh karena itu seleksi cukup ketat jika ingin bergabung (Zeng, Bu, \& Su, 2011:212). Fase terakhir Matang, keadaan inkubator telah stabil, permintaan untuk bergabung sangat tinggi sehingga perlu meningkatkan layanan untuk dapat ekspansi.

Menurut Timmons \& Spinelli (2008:41) proses kewirausahaan tidak hanya digunakan sebagai teori untuk mempertajam khazanah keilmuan kewirausahaan, namun perlu kombinasi dari praktik sehingga adanya keseimbangan yang terintegrasi dengan perubahan dan tantangan yang dihadapi. Proses kewirausahaan didukung berdasarkan faktor-faktor yang memengaruhi kesuksesan bagi usaha pemula menjadi usaha yang potensial. Faktor tersebut yaitu ragam bisnis, wirausahawan, geografi, dan teknologi. Adapun faktor pendukung lainnya, yakni semangat meraih peluang bisnis, digerakkan oleh wirausahawan, dan tim yang terkemuka, hemat dan kreatif mengelola sumber daya, sadar terhadap kesesuaian dan keseimbangan, dan terintegrasi dan holistik. Dibutuhkan peran seorang wirausahawan dan tim untuk menyeimbangankan faktor pendorong yang mendasari kesukesesan bagi usaha yang terdiri dari peluang usaha, strategi, jaringan, tim, dan rencana bisnis. Sehingga muncul bagan Timmons untuk menentukan bentuk dan ukuran dalam peluang, tim, dan sumber daya (Timmons \& Spinelli, 2008:42). 


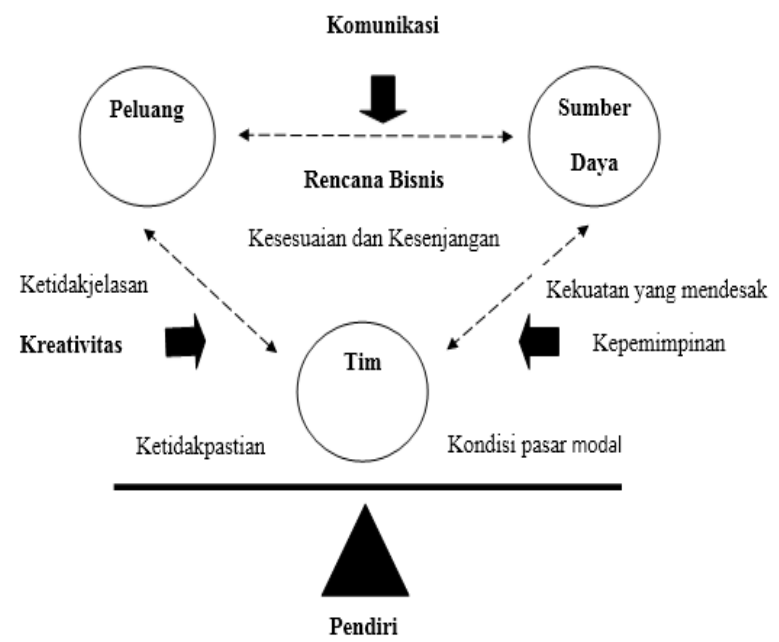

Gambar 1. Bagan timmons dalam proses kewirausahaan

Sumber: Timmons \& Spinelli (2008:42)

Keberadaan bagan Timmons berawal dari sebuah penelitian disertasi doktoral di Harvard Business School tentang perusahaan baru dan perusahaan sedang berkembang (Timmons \& Spinelli, 2008:49). Proses kewirausahaan memiliki sifat dinamis. Peluang terjadi karena ketidakpastian lingkungan. Maka rencana bisnis dibutuhkan sebagai alat komunikasi dari ketiga faktor yaitu peluang, tim, dan sumber daya (Timmons \& Spinelli 2008: 41).

\section{METODE}

Jenis penelitian yang digunakan adalah deskriptif. Penelitian deskriptif menguraikan secara detail hasil analisis data dari berbagai sumber penelitian terhadap gambaran individu dan fenomena. Menurut Ghony \& Almanshur (2012:89) informan adalah seorang yang terlibat dalam penelitian kita. Informan berfungsi sebagai orang yang dimanfaatkan untuk memberikan informasi sesuai dengan kondisi dan situasi dari penelitian, serta membantu agar informasi cepat didapatkan, teliti dalam menganalisis (Indrawan \& Yaniawati, 2014:37). Selain itu, menurut Sugiyono (2015:147), kriteria sebagai informan yaitu orang yang memahami dan mendalami proses obyek penelitian, orang yang masih terlibat dalam kegiatan yang diteliti, orang yang memiliki waktu untuk memberikan informasi pada peneliti, orang yang tidak cenderung menyampaikan informasi dari hasil sendiri, dan orang yang tidak memiliki keterlibatan terhadap peneliti.

Informan didapatkan berdasarkan persetujuan yang bersangkutan dan kriteria dari peneliti (Ghony \& Almanshur, 2012:147). Maka peneliti memilih informan yakni Bapak Iwan Iwut Tritoasmoro selaku Ketua Pengelola StartupCorner, Bapak Eko Rahayu, selaku Pengelola StartupCorner, dan lima founder dari lima startup (PT Aruna Jaya Nusantara, Modegi, Sociocaster, RadoCare, dan Smash) yang direkomendasikan oleh pengelola StartupCorner sebab lima startup tersebut mendapatkan pendanaan di luar dari StartupCorner karena kelima founderstartup yang bergabung dan mengikuti program Startup Corner. Dalam pengumpulan data, peneliti menggunakan triangulasi, yang berarti teknik pengumpulan data dengan menggabungkan sumber dan data yang telah ada. Triangulasi teknik diartikan teknik pengumpulan berbeda data berdasarkan sumber dan data yang sama (Sugiyono, 2015:242). Peneliti menggunakan observasi partisipatif, wawancara mendalam, dan dokumentasi untuk sumber data yang sama secara bersama. Semua diwawancara sampai memperoleh penjelasan yang jenuh dan mengarah pada jawaban yang sama.

Berikut adalah pokok-pokok telaah dalam penelitian kualitatif ini, seperti pada tabel berikut. 
Tabel 1. Pokok-pokok telaahan

\begin{tabular}{ll}
\hline Konsep & Deskripsi \\
\hline \multirow{3}{*}{ Peluang } & Ide: Sarana bagi seorang kewirausahaan di mana proses untuk mengubah \\
& kreativitas dalam menghadapi peluang. \\
& Permintaan Pasar: Tolak ukur utama dalam menilai sebuah peluang. \\
& Pemimpin: Seorang yang menentukan derap kerja dan iklim kerja dalam tim. \\
Tim & Kualitas Tim: Tim yang memiliki semangat berhasil, tekun dan ulet, kreatif \\
& dan mampu menghadapi ketidakpastian, risiko, dan perubahan. \\
& Aset: Aset fisik seperti pabrik, infrastruktur, bangunan, dan perlengkapan. \\
& Sumber Daya Manusia Orang Lain: Sumber Daya Manusia yang mendukung \\
Sumber Daya & perkembangan bisnis dan mengontrol sumber daya. Dikarenakan kekurangan \\
& tenaga kerja, dana, dan perlengkapan.
\end{tabular}

Sumber: Timmons \& Spinelli (2008)

Analisis data adalah proses mencari dan menyusun secara sistematis data yang diperoleh dari hasil observasi, wawancara, catatan lapangan, dan dokumentasi dengan cara mengorganisasikan data ke dalam kategori, menjabarkan ke dalam unit-unit, melakukan sintesa, menyusun ke dalam pola, memilih mana yang penting dan yang akan dipelajari dan membuat kesimpulan sehingga mudah dipahami oleh diri sendiri maupun orang lain (Sugiyono, 2015:368). Menurut Miles \& Huberman dalam Sugiyono (2015:369) analisis data kualitatif dilakukan pada saat pengumpulan data berlangsung dan setelah selesai pengumpulan dalam penelitian periode tertentu. Pada saat wawancara, peneliti sudah melakukan analisis apabila belum merasa memuaskan maka peneliti melanjutkan pertanyaan sampai diperoleh data yang kredibel.

\section{HASIL DAN PEMBAHASAN}

\subsection{Konsep peluang}

Terdapat jalur eksternal untuk calon startup, diharapkan output-nya menjadi perusahaan berbasis teknologi dan perusahaan dengan proses seleksi StartupCorner yakni pra inkubasi dan inkubasi. Seleksi yang dilakukan berdasarkan tiga kriteria yaitu pertama, ide, kreativitas, dan gagasan yang dapat diukur dengan potensi. Kedua, tim yang kompak, serta ketiga, pemilihan teknologi sudah tepat bahkan sudah memiliki prototipe produk sehingga ketiga kriteria tersebut diterima. Sesuatu yang dikatakan sebagai peluang belum tentu memiliki ide yang baik. Seorang wirausahawan harus mampu memutuskan sebuah ide yang layak yang dapat menyelesaikan suatu masalah (Timmons \& Spinelli, 2008:42).

Peluang bisa tercipta dari ide dan permintaan pasar. Ide adalah sarana bagi wirausahawan dalam proses untuk mengubah kreativitas dalam menghadapi peluang. Penerapan StartupCorner dalam mempertajam ide startup yang dijalankan oleh kelima startup yakni Radocare, Sociocaster, PT Aruna Jaya Nusantara, Modegi, dan Smash melalui sebuah pengembangan model bisnis, pengembangan produk, pelatihan business development, dan keilmuan tentang startup yang disesuaikan dari kebutuhan tiap startup yang terlibat. Permintaan pasar adalah tolak ukur utama dalam menilai sebuah peluang. Dalam memahami potensi pasar maka pengelola StartupCorner membantu para startup dalam menerjemahkan permintaan pasar, memberikan pengarahan proses bisnis yang diimplementasikan dalam sebuah kajian teori terkait business development, selain itu mengarahkan startup dalam memahami kebutuhan pelanggan atau umpan balik dari pelanggan.

Sebagaimana dari pernyataan di atas, Radocare mendapatkan pelatihan dalam mempertajam ide dari produk at bisnis yang dijalankan. Startup ini terbentuk dari hasil bimbingan tugas akhir yang dibimbing oleh Bapak Bambang dan diarahkan oleh BTP untuk mengkomersialisasikan produk Radocare melalui pembentukan startup. Kendati demikian, terdapat peluang terbentuknya produk Radocare yaitu satu-satunya produk di Asia dengan fungsi untuk membantu dokter gigi dalam mengidentifikasi penyakit gigi. Produk Radocare dapat digunakan tanpa power supply, tujuannya untuk menjangkau beberapa daerah di Indonesia yang masih terpencil yang belum memiliki fasilitas medis dan sumber daya listrik yang memadai. Maka produk tersebut dipadukan dengan penggunaan baterai sehingga dokter gigi yang berada di daerah pedalaman dapat menggunakan produk tersebut. 
Demi keberlanjutan Radocare maka StartupCorner turut andil dalam perancangan aplikasi dan hardware-nya. Startup corner membina Radocare pengembangan model dan proses bisnis yang telah memiliki kebutuhan pasar dan segmentasi yang jelas. Alhasil, Radocare telah memiliki lima calon pembeli dengan harga sekitar Rp 6.000 .000 per produk dan garansi satu tahun. Namun belum dipasarkan sebab masih tahap akhir pengembangan produk.

Sociocaster bergabung bersama StartupCorner yang sebelumnya mengembangkan sendiri bersama tim, kemudian masuk ke StartupCorner sehubungan dengan program Kemerinstek Dikti. Namun menurut Bapak Eko selaku Manager Operation StartupCorner bahwa Sociocaster tidak dari awal berasal dari inkubator lain karena inkubator tersebut tidak memenuhi syarat program Inkubasi Bisnis Teknologi/IBT (Kemenristek) akhirnya dialihkan ke StartupCorner untuk dibina. Peluang yang terbentuk dari startup ini diperuntukkan bagi jenis bisnis atau Usaha Menengah Kecil (UKM), memudahkan UKM dalam mengelola akun social media management mereka tanpa harus mengelola satu per satu. Sociocaster mendapatkan pembinaan dari StartupCorner dalam hal menganalisis ide hingga pengembangan produk. Sebagai contoh, Startup Corner memberikan arahan dalam melakukan pendekatan terhadap pasar Indonesia sehingga penawaran harga kepada pelanggan yang mampu menyesuaikan dengan permintaan pasar dan menciptakan pasar baru yakni pelanggan di Indonesia.

Tidak hanya itu, pengembangan model bisnis juga diterapkan atas saran dari StartupCorner yaitu awal mula pembayaran aplikasi dibayarkan dimuka dengan mendapatkan seluruh fitur dan dapat berlangganan secara penuh, lalu ditambahkan model bisnis yang baru yakni pelanggan dapat membayar per bulan maka akan mendapatkan fitur yang lebih banyak dibandingkan sekali bayar. Selain itu Sociocaster juga dipertemukan dengan bagian business service Telkom untuk pembinaaan UKM.

Selama bergabung bersama StartupCorner PT Aruna Jaya Nusantara mendapatkan pelatihan dan pembekalan terkait penerapan business development, model bisnis, serta networking yang berkecimpung di pemerintahan sehingga jangkauan pasar semakin luas. PT Aruna Jaya Nusantara melihat peluang dari potensi pasar yang luas, apalagi pasar di Indonesia terhadap pelelangan ikan tercatat sekitar 58 triliun atau sekitar 6,4 billion USD total pendapatan per tahun. Tentunya masih banyak pelelangan yang belum tercatat yang berpotensi bagi mafia-mafia pelelangan ikan. Di Asia pasar pelelangan ikan sekitar 25 billion USD. Pertumbuhan Ekonomi di Indonesia 9\% dan sekitar 8,8\% disumbangkan dari sektor perikanan, secara ekonomi sektor perikanan menjanjikan sehingga mampu mengundang investor dikutip dari CEO PT Aruna Jaya Nusantara.

Awal masuk PT Aruna Jaya Nusantara di StartupCorner mengikuti perlombaan yang bernama KlikStart yang dicetus oleh StartupCorner itu sendiri. Atas kemenangan perlombaan tersebut akhirnya Bapak Iwan Iwut mengajak PT Aruna Jaya Nusantara untuk mengikuti program inkubasi BTP atau disebut dengan StartupCorner. Karena PT Aruna Jaya Nusantara tetap berkelanjutan maka PT Aruna Jaya Nusantara mengikuti co-inkubasi untuk mendapatkan pendanaan lebih namun sebelum pendaftaran di Indigo, PT Aruna Jaya Nusantara diberikan pelatihan untuk mempertajam ide dalam penerapan model bisnis, market validation, dan customer validation. Selain itu, StartupCorner juga mengarahkan PT Aruna Jaya Nusantara pada pendekatan customer segmentation ke pemerintah. Hal serupa dialami oleh Modegi yang bergabung bersama StartupCorner dengan mencari program BTP yang mulanya ingin mencetak prototipe. Lalu, mengikuti program StartupCorner melalui tahap seleksi, pra inkubasi, hingga inkubasi. Pada proses pengembangan produk dengan memberikan pelatihan terkait packagingdan pengembangan produk perangkat keras dan lunak, user Interface, serta user experience sehingga para startup bergabung juga mendapatkan peluang untuk soft launching di PT Telkom Indonesia. Produk Modegi dapat digunakan untuk penghematan listrik yang setiap hari dikonsumsi. Tidak hanya rumah namun penggunaan produk Modegi dapat diimplementasikan untuk kantor dengan mempermudah aktivasi lampu, serta pabrik untuk mengurangi emisi pabrik sebab biaya listrik gudang.

Berbeda halnya dengan Smash yang tidak mendapatkan pembekalan terkait mempertajam ide begitupun terhadap pengembangan produknya dikarenakan Smash terbentuk sudah lama sebelum tercetusnya StartupCorner. Namun Smash lebih terlibat secara internal dengan memberikan saran koneksi dan peluang permintaan pasar, salah satu contoh saat StartupCorner mempertemukan Smash dengan pemerintah di Kabupaten Samosir untuk penerapan aplikasi My Smash, Smash mendapatkan peluang dalam mewujudkan bank sampah dalam versi mobile. Meninjau dari jumlah sampah serta persebaran bank sampah yang ada di Indonesia, kegiatan sosial yang melibatkan efisiensi sampah 
sudah marak diadakan maka dari itu My Smash membuat invasi untuk mengintegrasikan bank sampah ketitik terdekat user.

Sebelum mendapatkan pendanaan lebih oleh Indigo, Smash bergabung di StartupCorner, hal tersebut karena CEO dari Smash sendiri merupakan pihak internal BTP. Tetapi secara ide dan personal Smash mendapatkan informasi kegiatan-kegiatan dan peluang networking, salah satunya mengikuti co-inkubasi bersama Indigo. Smash resmi bergabung di StartupCorner sejak 2016, ke depannya empat orang tim Smash akan mengikuti program yang dilaksanakan oleh StartupCorner. Berdasarkan Gambar 2 dapat dilihat jalur masuk startup yang bergabung.

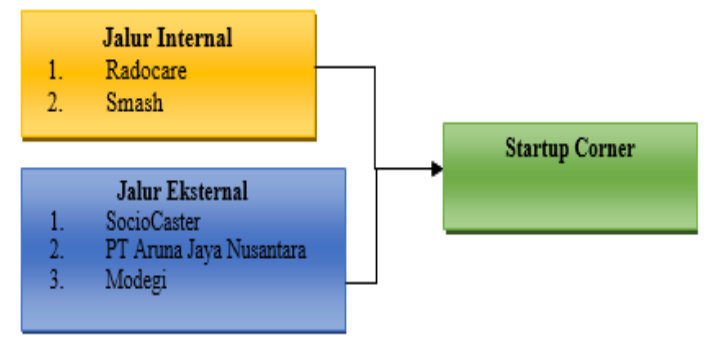

Gambar 2. Jalur masuk startup yang bergabung

Sumber: Wawancara peneliti dengan lima startup

Berdasarkan konsep keberhasilan peluang untuk menghasilkan suatu startup andal dengan ide yang brilian, maka tugas utama Startup Corner adalah memilih startup yang bergabung berdasarkan tiga kriteria yakni ide dan gagasan, tim, dan teknologi dengan adanya potensi pasar. Sehingga konsep peluang yang didapatkan pada startup yang bergabung yaitu dalam pengembangan produk, model bisnis, penentuan harga, penerjemahan kebutuhan pelanggan maka akan mendapatkan peluang untuk memperluas pasar dan koneksi bersama partnership.

\subsection{Konsep tim}

Tim merupakan aspek-aspek utama dari startup sudut pandang venture, kesalahan kerap terjadi bukan hanya pada ide akan tetapi orang yang bergabung adalah orang yang tidak tepat. (Timmons \& Spinelli, 2008:44). Diperlukan pemimpin yang mampu memimpin derap kerja dan iklim dalam tim (Timmons \& Spinelli, 2008:66-73).

Investor akan menilai dari kualitas sebuah tim di mana investor mencari startup yang penuh semangat, enerjik, dan motivasi yang tinggi, mampu menghadapi ketidakpastian, risiko, dan perubahan. Dari penjelasan di atas dapat digambarkan bahwa dimensi tim terbagi atas dua yaitu pemimpin adalah seseorang yang menentukan derap kerja dan iklim dalam membangun karakteristik kewirausahaan. Maka dalam penelitian ini peneliti mengambil gambaran melalui pembentukan karakter kewirausahaan terhadap dimensi pemimpin.

Selanjutnya dimensi kualitas tim pada proses pembentukan atau perekrutan tim dan budaya kerja yang diterapkan pada startup (Ramdhan, 2016:38). Umumnya StartupCorner memberikan pelatihan saat pra inkubasi mengenai karakter kewirausahaan, meliputi leadership dan mentalitas seorang wirausaha. Menurut Ries (2011:33) startup didirikan oleh individu, perorangan, ataupun perusahaan untuk menciptakan produk atau jasa yang baru dalam menghadapi ketidakpastian yang tinggi.

Menurut Milstein (2014); dalam Saputra (2015:4) risiko yang dihadapi bagi startup yakni risiko teknikal, risiko customer, dan risiko model bisnis. Saat ini peran StartupCorner dalam pembentukan jiwa kepemimpinan didapatkan oleh startup yang bergabung melalui sebuah pelatihan agar dapat memiliki karakteristik kewirausahaan dan menghadapi tantangan dalam berwirausaha. Startup Corner secara insidental membantu perekrutan atau pembentukan tim namun jika startup membutuhkan anggota akan dihubungkan dengan komunitas dan lembaga terkait. Peran StartupCorner dalam menciptakan budaya kerja fleksibel kecuali untuk waktu kerja di ruang kerja atau coworking space menyesuaikan dengan jam kerja dalam BTP sehingga mengajarkan para stratup untuk bekerja selama 8 jam. Namun kenyataannya sebagian memilih untuk bekerja di laboratorium atau di Bandung Digital Valley. 
Pada Radocare dimensi pertama yaitu pemimpin. Tim Radocare mengikuti pelatihan terkait karakter kewirausahaan selama dua kali selama program inkubasi. Radocare menerapkan budaya akademisi yaitu membimbing mahasiswa dalam pengembangan produk serta mengikuti instruksi dari dosen. Pembentukan tim dan pembagian tugas dilakukan oleh tim dosen berdasarkan ide tugas akhir dari mahasiswa bimbingan Bapak Bambang sehingga budaya kerja dilaksanakan berdasarkan permintaan proyek. Selama inkubasi, budaya kerja tidak dirasakan oleh Radocare, ini dikarenakan proses perakitan produk lebih cenderung dilakukan di laboratorium karena peralatan perakitan yang lengkap dan akan menganggu startup yang lain. Sociocaster mengikuti pelatihan karakter kewirausahaan termasuk aspek-aspek dalam bisnis tapi tidak terkait karakteristik kewirausahaan karena materi tersebut kiranya telah didapatkan sebelum mengikuti program inkubator StartupCorner. Dari kasus tersebut, StartupCorner turut membantu dalam perekrutan tim melalui career centre development Universitas Telkom. Selain itu, budaya kerja yang diterapkan oleh Sociocaster tidak formal tetapi tetap profesional dengan menyesuaikan suasana kerja di StartupCorner untuk lebih displin. Meninjau dari pembagian tugas yang fleksibel, hal ini dikarenakan tim yang bergabung bersama Sociocaster masih minim dengan pembagian tugas lebih mengarah pada aspek programmingnya namun kurang di aspek pemasaran. PT Aruna Jaya Nusantara mendapatkan pelatihan kewirausahaan terutama mentalitas kewirausahaan meskipun pendiri berlatar belakang dari Jurusan Manajemen namun secara praktisi sangat berbeda dengan teori, sehingga para pendiri maish tetap aktif mengikuti pelatihan yang disediakan oleh Startup Corner. Maka dari itu, StartupCorner memberikan arah di pra inkubasi, sedangkan untuk pembentukan timnya dibentuk oleh PT Aruna Jaya Nusantara dengan pembagian tugas cofounder Utari di bidang keuangan dan pemasaran, Daka di bidang operasional dengan budaya kerja fleksibel tetapi mengikuti pola budaya kerja StartupCorner dengan menerapkan kedisplinan. Atmosfir kerja pada Startup Corner hening atau pasif namun pembinaan, pelatihan, dan monitoring masih tetap dijalankan oleh Startup Corner.

Sedangkan Modegi pertama kali bergabung di StartupCorner mendapatkan pelatihan dalam mental kewirausahaan dan kepimpinan. Sehingga pembentukan tim dibentuk sendiri oleh Modegi sebab persyaratan sebelum bergabung dan seleksi bersama StartupCorner terdiri dari tiga orang dengan pembagian tugas yang berbeda namun dalam perekrutan StartupCorner membantu dalam koneksi career centre di Universitas Telkom khususnya untuk karyawan magang dengan sumber daya manusia yang terbatas menutupi ruang kerja apabila kerja kurang dari 24 jam.

Hanya Smash yang belum mendapatkan pelatihan kewirausahaan. CEO Smash sendiri mendapatkan selama bekerja di BTP. Namun untuk pembentukan tim ataupun perekrutan serta budaya kerja belum didapatkan oleh Smash, hal tersebut karena Smash terbentuk sebelum bergabung di StartupCorner namun karena ada penawaran dari pihak BTP maka Smash bergabung di StartupCorner dan mengikuti program Indigo. Saat ini Smash diminta untuk memberikan mentoring di StartupCorner namun adanya kendala maka untuk saat ini Smash belum bisa bergabung. Dapat disimpulkan bahwa dari pihak StartupCorner peran di aspek tim memberikan pelatihan kewirausahaan dan pada kualitas tim yang terdiri dari pembentukan tim, diserahkan oleh startup yang bergabung. Startup Corner juga membantu dalam penyebaran informasi perekrutan anggota dalam startup yang bergabung dalam budaya kerja mengikuti jam operasional BTP. Dari sisi startup mendapatkan pelatihan kewirausahaan, pembentukan tim, dan perekrutan yang fleksibel, budaya kerja belum dirasakan penuh.

\subsection{Konsep sumber daya}

Menurut Organization for Economic Co-Operation and Development (OECD) dalam Utoyo (2016:195) terdapat minimal enam fasilitas inkubasi bisnis yang harus disediakan. Pertama, physical infrastructure merupakan tempat pengembangan usaha seperti ruang kerja, ruang rapat, internet, dan fasilitas lainnya. Keberadaan infrastruktur menunjang para startup untuk membawa atmosfir kerja yang profesional.

Kedua, management support dengan menyediakan kegiatan mentoring melalui mentor para startup dapat belajar dalam mengelola bisnis. Ketiga, technical support berupa pelatihan khusus tentang membangun produk sehingga produk dapat diterima oleh masyarakat. Keempat, access to finance menyediakan ketersediaan modal untuk menjalankan usaha menjadi kendala utama dan atau mempertemukan kepada pihak ketiga untuk memperoleh bantuan modal baik dari bank, angel 
investor, dan lain-lain. Kelima, legal service memberikan bantuan berupa konsultasi pendaftaran badan usaha dan Hak Kekayaan Intelektual.

Dilansir dari www.investopedia.com pada tanggal 16 Januari 2017 bahwa sumber daya terbagi atas dua yakni sumber daya tangible terdiri dari mesin dan infrastruktur,serta sumber daya intangible yang terdiri dari hak paten, copyrights, dan merek. Terkait sumberdaya, StartupCorner memberikan sumber daya fisik yakni aset yang dimaksud ialah aset fisik dan StartupCorner telah menyediakan coworking space, fasilitas olahraga, pantry, Mushola, 3D Printing, dan fasilitas lainnya yang disediakan oleh BTP untuk menunjang atmosfir kerja bagi startup yang bergabung. Aset fisik tersebut telah didapatkan bagi startup yang lolos inkubasi di StartupCorner termasuk lima startup yang telah mendapatkan pendanaan lebih. Sumber daya intangible meliputi sumber daya manusia orang lain yang mendukung perkembangan bisnis dan mengontrol sumber daya dikarenakan kekurangan tenaga kerja, dana, dan perlengkapan. Sejauh ini, StartupCorner memberi peran untuk legalitas badan usaha, hak paten, dan pemasaran bagi startup yang bergabung. Walaupun lima di antarannya telah memiliki legalitas badan usaha, startup terdaftar sebagai badan usaha seperti PasarLaut.com menjadi PT Aruna Jaya Nusantara dan Radocare yang telah mendapatkan Hak Paten.

Tiga di antaranya sedang dalam proses legalitas badan usaha yang dibantu oleh StartupCorner dan Bandung Digital Valley (BDV). Menurut pengelola startupCorner, StratupCorner telah menyediakan dalam membantu komersialisasi produk namun hal tersebut tidak didapatkan oleh kelima startup tersebut. Keuntungan mendapatkan hak paten ialah perusahaan kecil dapat mengalahkan perusahaan besar, sebab Hak Paten tidak memandang besar kecilnya suatu bisnis, dapat menggalang dana.Dari aspek sumber daya, peran StartupCorner memberikan dari segi fasilitas fisik, membantu dalam komersialisasi, legalitas badan usaha, HAKI, dan Hak Paten.

Namun untuk pendanaan StartupCorner tidak menyediakan karena pemasukan dari StartupCorner disesuaikan dengan pemasukan dari BTP maka startup diarahkan mengikuti co-inkubasi atau program akselerator seperti Indigo dan Kemenristek Dikti. Namun pada kasus Radocare, Tim Radocare berasumsi bahwa dana yang didapatkan berasal dari StartupCorner setelah peneliti menelusuri lebih lanjut. Menurut Bapak Iwan Iwut, Radocare mendapatkan pendanaan dari Yayasan Pendidikan Telkom dan Kemenristek Dikti. Dapat disimpulkan sumber pendanaan bagi kelima startup tersebut startup yang mendapatkan pendanaan dari Kemenristek yakni Radocare dan Sociocaster. Selain itu Radocare juga mendapatkan pendanaan dari Yayasan Pendidikan Telkom adalah Radocare. Kemudian yang telah mengikuti program co-inkubasi adalah PT Aruna Jaya Nusantara, Smash, dan Modegi. Dari hasil analisis penelitian ini dapat dijabarkan melalui Tabel 2. 
Tabel 2. Rincian manfaat atas peran BTP kepada para startup

\begin{tabular}{|c|c|c|c|c|c|c|c|}
\hline $\begin{array}{l}\text { Informan } \\
\text { (I.) }\end{array}$ & \multicolumn{2}{|c|}{ Peluang } & \multicolumn{2}{|c|}{ Tim } & \multicolumn{3}{|c|}{ Sumber Daya } \\
\hline I1 & $\begin{array}{c}\text { Ide } \\
\sqrt{ }\end{array}$ & $\begin{array}{c}\text { Permintaan Pasar } \\
\sqrt{ }\end{array}$ & $\begin{array}{c}\text { Pemimpin } \\
\sqrt{ }\end{array}$ & $\begin{array}{c}\text { Kualitas Tim } \\
\sqrt{ }\end{array}$ & $\begin{array}{c}\text { Aset } \\
\sqrt{ }\end{array}$ & $\begin{array}{l}\text { Sumber Daya } \\
\text { Orang Lain }\end{array}$ & $\begin{array}{c}\text { Sumber } \\
\text { Pendanaan } \\
\sqrt{ }\end{array}$ \\
\hline $\begin{array}{l}\text { dan } \\
\text { I.2 }\end{array}$ & $\begin{array}{l}\text { Pengembangan } \\
\text { produk, model } \\
\text { bisnis }\end{array}$ & $\begin{array}{c}\text { Memperluas } \\
\text { jangkauan pasar }\end{array}$ & $\begin{array}{c}\text { Memberikan } \\
\text { pelatihan karakter } \\
\text { kewirausahaan. }\end{array}$ & $\begin{array}{c}\text { Dukungan rekrutmen, } \\
\text { lingkungan yang } \\
\text { displin }\end{array}$ & Fasilitas fisik & $\begin{array}{c}\text { Legalitas dan } \\
\text { Komersialisasi }\end{array}$ & $\begin{array}{l}\text { Biaya Hosting } \\
\text { dan Domain }\end{array}$ \\
\hline & $\sqrt{ }$ & $\mathrm{x}$ & $\sqrt{ }$ & & $\sqrt{ }$ & $\sqrt{ }$ & $\mathrm{x}$ \\
\hline I. 3 & $\begin{array}{l}\text { Pengembangan } \\
\text { produk dan } \\
\text { pengembangan } \\
\text { model bisnis }\end{array}$ & $\begin{array}{l}\text { Telah memiliki } \\
\text { pelanggan } \\
\text { spesifk }\end{array}$ & $\begin{array}{c}\text { Membentuk karakter } \\
\text { kewirausahaan } \\
\text { melalui pelatihan }\end{array}$ & $\begin{array}{l}\text { Pembentukan tim } \\
\text { dilakukan dari } \\
\text { Radocare, produksi } \\
\text { produk di } \\
\text { laboratorium }\end{array}$ & $\begin{array}{l}\text { Mendapatkan } \\
\text { fasilitas fisik }\end{array}$ & $\begin{array}{c}\text { Membantu } \\
\text { dalam legalitas }\end{array}$ & $\begin{array}{c}\text { Yayasan } \\
\text { Pendidikan } \\
\text { Telkom dan } \\
\text { Kemenristek } \\
\text { Dikti }\end{array}$ \\
\hline & $\sqrt{ }$ & $\frac{\mathrm{x}}{\text { Berdasarkan }}$ & $\frac{\mathrm{x}}{\text { Membentuk }}$ & $\sqrt{ }$ & $\sqrt{ }$ & $\sqrt{ }$ & $\mathrm{x}$ \\
\hline I.4 & $\begin{array}{l}\text { Pengembangan } \\
\text { model bisnis dan } \\
\text { harga jual produk }\end{array}$ & $\begin{array}{l}\text { Berdasarkan } \\
\text { ticket support } \\
\text { permintaan } \\
\text { pelanggan }\end{array}$ & $\begin{array}{c}\text { Membentuk karakter } \\
\text { kewirausahaan } \\
\text { melalui pelatihan pra } \\
\text { inkubasi }\end{array}$ & $\begin{array}{l}\text { Mendapatkan bantuan } \\
\text { dalam menyebarkan } \\
\text { informasi perekrutan }\end{array}$ & $\begin{array}{l}\text { Mendapatkan } \\
\text { fasilitas fisik }\end{array}$ & $\begin{array}{c}\text { Membantu } \\
\text { dalam legalitas }\end{array}$ & $\begin{array}{c}\text { Kemenristek } \\
\text { Dikti }\end{array}$ \\
\hline & $\sqrt{ }$ & $\sqrt{ }$ & $\frac{\sqrt{ }}{\text { Membentuk karakter }}$ & $\frac{\mathrm{x}}{\text { Membentuk tim }}$ & $\sqrt{ }$ & $\mathrm{x}$ & $\mathrm{x}$ \\
\hline I. 5 & $\begin{array}{c}\text { Pengembangan } \\
\text { model bisnis }\end{array}$ & $\begin{array}{c}\text { Memperluas } \\
\text { jangkauan pasar }\end{array}$ & $\begin{array}{c}\text { kewirausahaan } \\
\text { melalui pelatihan pra } \\
\text { inkubasi }\end{array}$ & $\begin{array}{c}\text { sendiri dan tidak } \\
\text { merasakan suasana } \\
\text { inkubasi }\end{array}$ & $\begin{array}{l}\text { Mendapatkan } \\
\text { fasilitas fisik }\end{array}$ & Legalitas BDV & $\begin{array}{c}\text { Indigo dan Angel } \\
\text { Investor }\end{array}$ \\
\hline & $\sqrt{ }$ & $\sqrt{ }$ & $\sqrt{ }$ & $\sqrt{ }$ & $\sqrt{ }$ & $\sqrt{ }$ & $\mathrm{x}$ \\
\hline I.6 & $\begin{array}{c}\text { Pengembangan } \\
\text { model bisnis dan } \\
\text { pengembangan } \\
\text { produk }\end{array}$ & $\begin{array}{l}\text { Membantu dalam } \\
\text { melakukan soft } \\
\text { launching }\end{array}$ & $\begin{array}{c}\text { Membentuk karakter } \\
\text { kewirausahaan } \\
\text { melalui pelatihan pra } \\
\text { inkubasi }\end{array}$ & $\begin{array}{l}\text { Mendapatkan bantuan } \\
\text { dalam menyebarkan } \\
\text { informasi perekrutan }\end{array}$ & $\begin{array}{l}\text { Mendapatkan } \\
\text { fasilitas fisik }\end{array}$ & $\begin{array}{c}\text { Membantu } \\
\text { dalam legalitas }\end{array}$ & Indigo \\
\hline & $\mathrm{x}$ & $\sqrt{ }$ & $\mathrm{x}$ & $\mathrm{x}$ & $\sqrt{ }$ & $\mathrm{x}$ & $\mathrm{x}$ \\
\hline I. 7 & $\begin{array}{c}\text { Pengembangan ide, } \\
\text { produk, dan model } \\
\text { bisnis dilakukan } \\
\text { oleh Smash }\end{array}$ & $\begin{array}{l}\text { Mendapatkan } \\
\text { peluang } \\
\text { pelanggan dan } \\
\text { mendapatkan } \\
\text { dukungan } \\
\text { personal } \\
\end{array}$ & $\begin{array}{c}\text { Belum mendapatkan } \\
\text { pelatihan } \\
\text { kewirausahaan }\end{array}$ & $\begin{array}{c}\text { Proses perekrutan, } \\
\text { pembentukan tim dan } \\
\text { budaya kerja dibentuk } \\
\text { Smash }\end{array}$ & $\begin{array}{l}\text { Mendapatkan } \\
\text { fasilitas fisik }\end{array}$ & Legalitas BDV & $\begin{array}{l}\text { In Code dan } \\
\text { Indigo }\end{array}$ \\
\hline
\end{tabular}

\section{SIMPULAN DAN SARAN}

Simpulan yang dapat diuraikan adalah peran StartupCorner dalam mengembangkan startup dari aspek peluang, berdasarkan dimensi ide telah berperan dalam pengembangan produk dan model bisnis, harga jual, kemudian dimensi kedua yaitu permintaan pasar peranan StartupCorner yaitu mengarahkan dalam menerjemahkan pelanggan sehingga dapat membantu dalam mencapai peluang pelanggan dan memperluas jangkauan pasar. Selanjutnya peran StartupCorner dalam mengembangkan startup dari aspek tim berdasarkan dimensi pemimpin dan kualitas tim. StartupCorner telah berperan pada dimensi pemimpin melalui sebuah pelatihan untuk membentuk karakter kewirausahaan saat kegiatan pra inkubasi. Dalam menciptakan kualitas tim diserahkan kepadastartup yang bergabung namun budaya kerja disarankan untuk bekerja displin sesuai dengan jam kerja BTP selain itu StartupCorner membantu dalam menyebarkan informasi perekrutan bagi startup yang membutuhkan anggota. Dan peran StartupCorner dalam mengembangkan startup dari aspek sumber daya, StartupCorner telah memberikan fasilitas fisik, kemudian bantuan untuk membuat legalitas badan usaha, hak paten namun tidak ada bantuan dana untuk keberlanjutan suatu startup.

Saran yang dapat diajukan kepada StartupCorner terkait penelitian ini, yaitu ke depannya diharapkan startup yang bergabung dapat mengikuti pelatihan dengan berkolaborasi salah satu wadah startup dibawah naungan Telkom Group yaitu Amoeba sebagai wadah pertajam ide dan menerjemahkan permintaan pasar dan pelanggan secara luas.

Pada konsep tim diharapkan tidak hanya di pra inkubasi tetapi selama inkubasi startup diberikan pembekalan sesuai yang dihadapi dengan mengadakan sharing session ataupun pendampingan mentor dari pihak eksternal. Hal tersebut dikarenakan pemecahan masalah dari pihak eksternal beragam sehingga dapat dijadikan pembelajaran dan berbagi pengalaman. Terbukti hingga saat ini startup yang mendapatkan pendanaan lebih hanya terdapat lima startup.

Menurut Inamato; dalam Utoyo (2016:183) pada saat proses seleksi diperlukan kejelasan pembagian tugas dan tanggung jawab masing-masing personel dalam suatu startup, misalnya personel yang bertugas dalam public relation, investment product, ataupun coding sehingga program 
pelatihannya diberikan oleh Startup Corner fokus berdasarkan pembagian tugas tersebut. Selain itu, penting untuk membangun suasana startup dengan desain kantor yang lebih mengarah suasana yang unik untuk menciptakan semangat bagi para tim startup. Namun, di sisi lain promosi terkait StartupCorner masih kurang dijalankan baik segi internal maupun eksternal.

Penelitian dapat dilajutkan terkait dengan performa pada masing-masing startup setelah mengikuti masa inkubator di BTP, terutama dengan mengungkapkan kinerja keuangan (profit, investasi, nilai asset, dan margin) dan non keuangan (market share, brand awareness, penetrasi pasar, dan lainnya), sehingga dapat menilai keberhasilan BTP sebagai perantara kesuksesan para startup menjadi unicorn di Indonesia.

\section{ACKNOWLEDGEMENTS}

Ucapan terima kasih disampaikan kepada seluruh pihak informan dalam penelitian ini yaitu para pimpinan perusahaan startup yang kami wawancara, terutama pihak BTP Telkom University yang telah bercerita banyak mengenai program StartupCorner.

\section{REFERENSI}

Adhitama, B. (2015). The impact of sosial entrepreneurship dimension of Timmons Model to the future Indonesian batik (A case study of Ikatan Pencinta Batik Nusantara) (Master's Thesis, Telkom University. Unpublished)

Aditya, H. (2016, 4 November). 5 strategi pemerintah untuk "Melahirkan" 1.000 startup digital di Indonesia. Diperoleh dari https://id.techinasia.com/pemerintah-luncurkan-gerakan-nasional-1000startup-digital/

Arjanti, A.R. \& Mosal, L.R. (2012). Startup indonesia! Inspirasi dan pelajaran dari para pendiri bisnis digital. $1^{\text {st }}$ Edition, Jakarta: PT Kompas Media Nusantara

Berkowski, G. (2016). How to build a billion dollar app: Temukan rahasia dari para pengusaha aplikasi paling sukses di dunia. $1^{\text {st }}$ Edition, Jakarta: Gemilang

Bessant, J. \& Tidd, J. (2007). Innovation and entrepreneurship. $2^{\text {nd }}$ Edition, West Sussex, England: John Wiley \& Sons Ltd

Brem, A. \& Borchardt. (2014). Technology entrepreneurship innovation and intrepreneurship managing entrepreneurial activities in technology-intensive environments. Handbook of research on technopreneurship: How technology and entrepreneurship are shaping the development of industrie and companies. $1^{\text {st }}$ Edition, West Sussex, England: John Wiley \& Sons Ltd

Cimahi Techno Park. (2017, Januari 16). Soft launching Cimahi Technopark. Diperoleh dari https://cimahitechnopark.wordpress.com/2016/10/25/soft-launching-cimahi-technopark/

Ghony, D. \& Almanshur. (2012). Metode penelitian kualitatif. $4^{\text {th }}$ Edition, Jogjakarta: AR-Ruzz Media

Hasbullah, R. (2015). Peran inkubator bisnis perguruan tinggi dalam peningkatan kinerja usaha UKM pangan. Jurnal Ilmu Pertanian Indonesia (JIPI), 12(1), 9-20

Hisrich. (2008). Kewirausahaan. $7^{\text {th }}$ Edition, Jakarta: Salemba Empat

Indrawan, R. \& Yaniawati, R. (2014). Metodologi penelitian kuantitatif, kualitatif, dan campuran untuk manajemen, pembangunan, dan pendidikan. $2^{\text {nd }}$ Edition, Bandung: PT Reflika Aditama

Isabelle, D.A. (2014). Capitalization of science and technology knowledge: Practices, trends and impacts on techno-entrepreneurship. Handbook of research on technopreneurship: How technology and entrepreneurship are shaping the development of industrie and companies. $2^{\text {nd }}$ Edition, Wiesbaden: Gabler

Mason, C. \& Strak. (2004). What do investors look for in a business plan? A comparison of the investment criteria of bankers, venture capitalists, and business angels. International Small Business Journal.22(3), 227-248

Pauwels \& Charlotte. (2016). Understanding a new generation incubation model: The accelerator. Technovation,12(1), 13-24

Phillimore, J. (2013). Science parks: A triumph of hype over experience?. In L.V. Shavinina (eds.). The International Handbook on Innovation. $2^{\text {nd }}$ Edition, Kiddlington, UK: Elsevier 
Profil Bandung Techno Park. (2016, November 4). Diperoleh dari http://bandungtechnopark.com/profil/

Profil startup corner. (2016, November 4). Diperoleh dari http://startupCorner.com/profil/

Rahman, L.F. (2012). Strategy development of PT. XYZ astartup technology company, The Indonesian Journal of Business Administration, 5(2), 6-11

Ramdhan, H.F. (2016).Startupreneur: Menjadi entrepreneur startup. Jakarta: Penebar Swadya Grup

Rhonda, A. (2012). En.Tre.Pre.Neur.Ship. $4^{\text {th }}$ Edition, Upper Saddler River, United States of America: Planningshop, Inc

Ries, E. (2011). The lean startup: How today's entrepreneurs use continuous innovation to create radically successful businesses. New York, USA: Fletcher \& Company

Saputra, A. (2015). Peran inkubator bisnis dalam mengembangkan digital startup lokal di Indonesia.Jurnal Ilmiah Mahasiswa Universitas Surabaya, 4(1), 1-24

Sitepu, S.N. (2016). Kolaborasi dan inovasi pada kegiatan mentoring dan eksekusi bisnis untuk mendorong keberhasilan start-up bisnis. ProsidingKonferensi Nasional Riset Manajemen X, 2-14

Siyanbola, W.O. (2011). Framework for technological entrepreneurship development: Key issues and policy directions. America Journal of Industrial and Business Management, 1, 10-19

Soenarso, W., Nugraha, D., \& Listyaningrum, E. (2013). Development of Science and Technology Park (STP) in Indonesia to support innovation-based regional economy: Concept and early stage development. World Technopolis Association,11(3), 32-42

Sugiyono. (2015). Metode penelitian dan pengembangan: Research and development/R\&D. $5^{\text {th }}$ Edition, Bandung: ALFABETA

Tangible Asset. (2017, Januari 16). What is tangible asset? Diperoleh dari http://www.investopedia.com/terms/t/tangibleasset.asp

Thérin, F. (2014). Handbook of research on technopreneurship how technology and entrepreneurship are shaping the development of industrie and companies (2nd Ed.). Northampton, USA \& Cheltenham, UK: Elgar Edward Publishing

Timmons, A.J. \& Spinelli, S. (2008). New venture creation: Entrepreneurship for the 21th century. 6th Edition. Yogyakarta: ANDI

Utoyo, I. (2016). Silicon valley mindset. Jakarta: PT Gramedia Pustaka Utama

Wei, L., Zhu, Y., Deng, P., \& Yu, W. (2014). Identifying business incubators based on their real activities: Evidence from China. World academy of science, engineering, and technology. International Journal of Social, Behavioral, Educational, Economic, Business, and Industrial Engineering, 8(11), 3718-3725

Zeng, F., Bu, X., \& Su, L. (2011). Study on entrepreneurial process model for SIFE student team based on Timmons model. Journal of Chinese Entrepreneurship, 3 (3), 204-214

Zupic, I. (2014). The knowledge base of technology entrepreneurship. Handbook of research on technopreneurship: how technology and entrepreneurship are shaping the development of industrie and companies. $2^{\text {nd }}$ Edition, Northampton, USA \& Cheltenham, UK: Elgar Edward Publishing 
Jurnal Manajemen Maranatha — Vol. 19 Nomor 1, November (2019) 